\title{
MARXISMO E RELAÇÕES DE TRABALHO
}

\author{
ANDRÉIA GALVÃO ${ }^{1}$
}

O estudo das relações de trabalho (ou das relações industriais, termo utilizado pela literatura anglo-saxã) tem sido tradicionalmente realizado a partir de conceitos oriundos de referenciais teóricos conservadores, como a teoria do sistema de relações industriais, elaborada pelo norte-americano John Dunlop ${ }^{2}$. Embora tenha sido bastante criticada por seu caráter estático e hierarquizado, o aparato conceitual proposto por Dunlop é ainda utilizado por estudiosos interessados em analisar as regras que regem as relações de trabalho, mesmo que suas abordagens tenham um caráter progressista ${ }^{3}$.

O objetivo desta comunicação é apresentar as críticas feitas à teoria de Dunlop por autores ligados à perspectiva teórica marxista. Pretende-

\footnotetext{
${ }^{1}$ Doutora em Ciências Sociais pelo Instituo de Filosofia e Ciências Humanas (IFCH), da Universidade Estadual de Campinas (Unicamp) e professora do Departamento de Ciência Política da mesma Universidade.

2 John Dunlop, Industrial Relations Systems. Boston, Massachussetts: Harvard Business Scholl Press, 1993 [1958].

${ }^{3}$ Essa teoria foi retomada principalmente pela sociologia do trabalho francesa. Ver, a respeito, Jean-Daniel Reynaud (dir.), Systèmes des relations professionnelles: un examen théorique. Lyon: Éditions du CNRS, 1991; Gregor Murray, Marie-Laure Morin, Isabel Da Costa, L'état des relations professionnelles - traditions et perspectives de recherche. Toulouse: Octares Editions, 1996. Sua incorporação na literatura brasileira se deu especialmente através da economia do trabalho. Cf. Claudio S. Dedecca, Racionalização econômica e trabalho no capitalismo avançado. Campinas, S.P. :Unicamp/IE, 1999.
} 
se, especialmente, indicar as contribuições trazidas, a partir dos anos 70, por Richard Hyman ${ }^{4}$, Robert Cox $^{5}$ e John Kelly ${ }^{6}$ para o estudo das relações de trabalho.

$$
* * * * * *
$$

A noção de sistema de relações industriais inspira-se na concepção parsoniana de sistema social. Para a abordagem sistêmica, um sistema de relações industriais é um conjunto de instituições, práticas e procedimentos destinados à produção das regras que regem as relações de trabalho. É composto por "certos atores, certos contextos, uma ideologia que unifica o sistema como um todo, enfim por um corpo de regras cuja finalidade é reger os atores em seu lugar de trabalho e em sua vida no trabalho"?.

O termo ator refere-se àquele que age ou reage. São eles: as organizações dos trabalhadores e do patronato (que não precisam ser formais) e as instituições públicas especializadas, destinadas a assistir os dois "atores" em suas relações. Os "atores" de um sistema de relações industriais interagem no interior de uma rede ou meio, que compreende três elementos ou subsistemas: 1) o contexto tecnológico que enquadra as condições de trabalho e a vida no trabalho; 2) os constrangimentos econômicos e financeiros que pesam sobre os "atores"; 3) o contexto político, isto é, as relações de poder e a distribuição do poder na sociedade. Os "atores" que agem nos diferentes contextos se articulam por meio de uma ideologia - concebida pelo autor como um conjunto de idéias e valores comuns -, que assegura a estabilidade do sistema na medida em que une os "atores", possibilitando que se reconheçam como interlocutores legítimos.

\footnotetext{
${ }^{4}$ Richard Hyman, Industrial relations: a marxist introduction. London: The Macmillan Press, 1975 e "La théorie des rélations industrielles: une analyse matérialiste", Sociologie du Travail $\mathrm{n}^{\circ}$ 4, 1979.

${ }^{5}$ Robert Cox, "Pour une étude prospective des relations de production", Sociologie du Travail, $\mathrm{n}^{\circ}$ 2, 1977 e Production, power and world order. New York: Columbia University Press, 1987.

${ }^{6}$ John Kelly, Rethinking industrial relations. Mobilization, collectivism and long waves. Routledge: London School of Economics, 1998.

${ }^{7}$ Dunlop, Industrial Relations Systems, op. cit, p. 47.
}

38 MARXisMo E RELAÇÕES DE TRABALHO 
Os elementos que compõem o sistema são interdependentes: cada um possui uma função que lhes permite contribuir à manutenção e ao equilíbrio do todo. Embora Dunlop não negue a existência de conflitos de interesse entre empregadores e empregados, destaca a necessidade de atenuar e gerir esses conflitos através da negociação coletiva e dos demais elementos que integram o sistema. Parte do pressuposto de que os conflitos entre trabalhadores e empregadores, "desde que sejam enunciados claramente pelas instituições representativas legítimas, podem ser facilmente contidos e desarmados" ${ }^{\prime 8}$ O conflito é percebido como um sintoma superficial, uma disfunção ou um mal entendido, desempenhando um papel negligenciável ${ }^{9}$. Trata-se, portanto, de uma reação ao conceito marxista de relações de produção, que remete ao antagonismo de interesses que marca a relação entre capital e trabalho e à dinâmica da luta de classes ${ }^{10}$.

De uma perspectiva marxista, o termo sistema de relações industriais e seus equivalentes constitui um eufemismo destinado a encobrir as tensões e os conflitos existentes na relação capital X trabalho. Para o sociólogo inglês Richard Hyman (1975), trata-se de um conceito descritivo e não explicativo, que insiste na necessidade de conter e controlar os conflitos, calando-se sobre as razões de seu surgimento. Ao apontar os limites e as insuficiências dessa tradição, Hyman (1979) insiste que o conflito pode ser tanto agudo quanto latente: o fato do conflito não se manifestar abertamente não significa que ele deixou de existir.

\footnotetext{
${ }^{8}$ Hyman, Industrial relations: a marxist introduction, op. cit., p. 421.

${ }^{9}$ François Sellier, Les relations industrielles - principes et politiques. Paris, PUF, 1976.

${ }^{10} \mathrm{O}$ debate aqui apresentado retoma, portanto, oposições epistemológicas que remontam aos primórdios da sociologia. Enquanto Marx buscou compreender o funcionamento das relações de produção capitalista a fim de desvendar suas contradições e refletir sobre as possibilidades de superação do modo de produção capitalista, Durkheim tratou de considerá-las a partir de uma preocupação de ordem moral, compreendendo a divisão do trabalho alcançada pela grande indústria como fator de solidariedade e integração social. Com efeito, a teoria dunlopiana "tornou-se, nos anos 1950, a principal rival do marxismo para interpretar os problemas sociais e os problemas do trabalho " (Piore, Michael "Critiques sur le systeme de relations professionnelles de Dunlop" In: JeanDaniel Reynaud (dir.), Systèmes des relations professionnelles: un examen théorique. Lyon: Éditions du CNRS, 1991, p. 320.
} 
A primeira crítica que Hyman dirige à abordagem sistêmica é que ela pressupõe que as relações entre empregadores e trabalhadores são geralmente estáveis e ordenadas, descartando as contradições sociais e a existência de interesses antagônicos. Seu objetivo, ao contrário, é abordar as relações industriais enquanto relações de exploração e dominação, observando-as à luz da luta de classes. Sua análise compreende as relações capital $\mathrm{X}$ trabalho como um elemento da totalidade das relações sociais de produção que, longe de apresentarem um comportamento estável, compatível e integrado, possuem um caráter dinâmico e contraditório (Hyman, 1975).

O desenvolvimento teórico proposto por Hyman contempla a noção de praxis, frequientemente esquecida pelas diversas correntes de pensamento que acusam o marxismo de ignorar a dimensão subjetiva, o papel dos "atores sociais", como se esses fossem impotentes, incapazes de qualquer ação autônoma, simples marionetes manipuladas por estruturas impessoais que determinariam de antemão os rumos do processo histórico. Para Hyman, as relações sociais de produção se desenvolvem a partir de condições materiais que limitam o campo das escolhas dos indivíduos e grupos sociais, sem determinar mecanicamente as possibilidades de ação. Deste modo, opõe-se, de um lado, às análises economicistas, que negam qualquer possibilidade de praxis ao subsumir a ação da classe operária aos determinantes estruturais do capitalismo e, de outro, àquelas que consideram as possibilidades de ação operária ilimitadas, quaisquer que sejam as condições objetivas, pois tanto uma quanto a outra desconsideram "o duplo acento que [Marx] coloca sobre os determinantes estruturais da produção capitalista e sobre o agente histórico que é a classe operária em luta" ${ }^{11}$.

${ }^{11}$ Hyman, Industrial relations: a marxist introduction, op. cit., p. 437. Não por acaso, Hyman refere-se à classe operária como agente e não como ator. $\mathrm{O}$ termo ator possui duas conotações distintas: de um lado, permite supor que os indivíduos agem para representar um papel que já está dado, sem que tenham a possibilidade de interferir na definição de suas atribuições; de outro lado, pressupõe que os indivíduos são livres para agir como bem entendem, sem que sua ação seja condicionada por elementos de ordem estrutural e superestrutural. Ambas as leituras são restritivas, pois não dão conta das imbricações entre ação e constrangimentos: ou o indivíduo é completamente autônomo ou completamente subordinado a alguma determinação externa. A apreensão

40 MARXisMo E RELAÇÕES DE TRABALHO 
Hyman admite a existência de regras que regulam o mundo do trabalho e do emprego, bem como instituições que as elaboram e as implemen$\operatorname{tam}^{12}$. Porém, considera que definir o assunto exclusivamente em termos de regras e regulação é muito restritivo, pois não explica por que conflitos eclodem, não obstante a existência de regras destinadas a contê-los. As regras podem impedir provisoriamente a manifestação do conflito, pois institucionalizam as relações de trabalho, canalizando as formas de expressão de interesses e definindo procedimentos de negociação e resolução das divergências, mas não eliminam suas causas. Estas residem nas diferentes posições ocupadas na estrutura produtiva, ou seja, nas divisões de classe, e são alimentadas pela correlação de forças e pelas disputas ideológicas que marcam o contexto sócio-político em cada momento histórico. Para o autor, o conceito de sistema de relações industriais só tem valor analítico se incorpora a existência de processos e forças contraditórias, as fontes e as consequiências do conflito social. Assim sendo, as relações industriais devem ser compreendidas a partir de uma perspectiva dialética, "como um processo que gera conflito e desordem tanto quanto ordem e regulação"

A segunda grande crítica dirigida à teoria de Dunlop deve-se ao fato de que este privilegia as organizações de empregadores e trabalhadores en-

das implicações recíprocas estabelecidas entre as duas dimensões requer uma perspectiva dialética, que recuse um determinismo mecanicista. Para tentar escapar desse problema, Hyman opta pela utilização do termo agente - como, aliás, também faz Nicos Poulantzas em Pouvoir politique et classes sociales, Paris, Maspero, 1968 - a fim de designar um coletivo que age dentro de determinados limites estruturais, limites esses dados pelo seu pertencimento de classe. É verdade que a tradição weberiana também emprega o termo agente, mas num sentido distinto da tradição marxista, pois, para Weber, o agente é um indivíduo que atribui sentido à ação social.

${ }^{12}$ Ao se perguntarem por que todos aqueles que criticam o modelo sistêmico - incluindo Hyman - insistem em continuar a empregá-lo, concebendo variantes do conceito dunlopiano, Giles e Murray respondem que sua utilização se deve menos a sua capacidade teórica e "mais a sua aptidão em fornecer um retrato aparentemente científico do universo complexo das relações industriais" (Anthony Giles, Gregor Murray, "Trajectoires et paradigmes dans l'étude des relations industrielles en Amérique du Nord". In: Murray, Morin e Da Costa, L'état des relations professionnelles - traditions et perspectives de recherche, op. cit., p. 71).

${ }^{13}$ Hyman, Industrial relations: a marxist introduction, op. cit., p. 197. 
volvidas em negociações e acordos coletivos, reduzindo o estudo das relações industriais ao aspecto formal e institucional. Além disso, a ênfase na negociação minimiza as formas de repressão e de dominação ideológica existentes. Hyman, ao contrário, define relações industriais como "o estudo do processo de controle sobre as relações de trabalho"14, o que compreende não somente as formas de regulação do emprego, mas também formas não institucionalizadas de controle, a exemplo das relações de poder. Seu objetivo é, portanto, realizar uma "economia política das relações industriais"15.

Assim, Hyman amplia as esferas do controle e da regulação para além da dimensão legal-institucional, desmistificando a suposta neutralidade estatal e permitindo que os diversos modos de implicação do Estado nas relações capital $\mathrm{X}$ trabalho sejam incorporados à análise ${ }^{16}$. Desse modo, o autor redefine o conceito sistêmico pois, ao contrário de Dunlop, enfatiza a importância do conflito e minimiza a importância das regras. Além disso - e aqui reside a principal diferença entre os conceitos propostos por esses autores - Hyman busca explicar as causas do conflito: sua origem é estrutural, decorre da existência de uma sociedade de classes, ainda que nem sempre o conflito venha a se manifestar. Já para Dunlop, o conflito não é permanente e sim eventual: deve-se a um desentendimento, à falta de consenso, e não à assimetria da relação capital X trabalho.

As críticas introduzidas por Hyman levam-no a formular um outro conceito de sistema de relações industriais. No entanto, ao preservar o termo sistema, o autor se mantém, de alguma forma, preso à definição que lhe deu origem e acaba incorrendo num risco, uma vez que a expressão sistema de relações industriais é predominantemente associada à definição dunlopiana.

\footnotetext{
${ }^{14}$ Idem, p. 12.

15 Ibdem, p. 31.

${ }^{16}$ A maior parte dos trabalhos sobre relações industriais considera o papel do Estado enquanto legislador, empregador e definidor da política macroeconômica (ou como participante dos acordos tripartites, nos estudos sobre neocorporativismo), mas ignora sua relação com os interesses de classe e o processo de acumulação de capital (ou seja, passa longe da discussão sobre a natureza de classe do Estado, diferentemente de Hyman).
}

42 MARXiSMO E RELAÇÕES DE TRABALHO 
A nosso ver, a utilização do termo, ainda que com ressalvas, oculta a diferença conceitual entre o novo conceito e o antigo, conduzindo à ambigüidade e à imprecisão. Com isso, realizamos uma reprovação terminológica a Hyman, considerando inadequado usar um termo tradicionalmente identificado com uma perspectiva que se quer combater.

Outra tentativa de elaboração teórica a partir de um instrumental marxista foi empreendida pelo cientista político canadense Robert Cox, também nos anos 70. Cox (1977) aponta duas grandes limitações do conceito dunlopiano: seu conteúdo ideológico reformista e conservador, associado à compreensão dos representantes de capital e trabalho como "parceiros sociais", e o caráter restritivo do modelo, cujos traços correspondem aos países de capitalismo avançado, tornando-o inaplicável a qualquer estudo comparativo, tanto numa perspectiva sincrônica quanto diacrônica.

Segundo Groux (1992), o objetivo deste autor é mais ambicioso do que o de Hyman: Cox busca romper com a teoria das relações industriais, sobretudo com sua vertente dunlopiana, propondo substituí-la por uma teoria das relações sociais de produção, fundada em conceitos universais, capazes de apreender a origem e a transformação das estruturas sociais existentes. Para isso, ao invés do positivismo que caracteriza a abordagem dunlopiana, recorre ao materialismo histórico e dialético, compreendendo os acontecimentos sociais em sua dupla dimensão: objetiva e subjetiva, ou como resultado da interelação entre estrutura e superestrutura.

Se os objetivos desses autores variam, as críticas dirigidas à Dunlop são semelhantes. A exemplo de Hyman, Cox também prioriza a importância do conflito, denunciando a incapacidade da ênfase na produção de regras apreender as tensões que atravessam o sistema de relações industriais, e destaca o papel da teoria como instrumento de crítica social, opondo-se à perspectiva integracionista, dedicada à resolução de problemas. O emprego do método histórico-estrutural permite-lhe considerar a institucionalização dos conflitos como uma fase histórica intermediária, sujeita a ser questionada e, portanto, modificada (Cox, 1977). 
Cox utiliza esse amálgama de elementos objetivos e subjetivos para explicar a origem do conflito. Segundo o autor, o conflito nasce da conjunção entre, de um lado, as condições objetivas geradas pelas relações de produção e, de outro, as formas de consciência que caracterizam indivíduos e grupos sociais. A simples produção de condições potencialmente conflitantes não leva necessariamente à eclosão de conflitos; para isso, é preciso que os atores tomem consicência dessa situação e que se percebam como um grupo com demandas e estratégias de ação próprias. A eclosão de um conflito, por sua vez, não leva inexoravelmente à transformação estrutural pois, para isso, é necessário haver uma mudança na posição de poder relativa dos grupos sociais e a emergência de novas ideologias dominantes, de modo que a coalizão anteriormente hegemônica seja substituída.

Recentemente, um outro autor identificado com o marxismo dedicou-se ao estudo da questão: John Kelly, professor do departamento de relações industriais da London School of Economics. Assim como seus predecessores, Kelly (1998) compreende como objeto das relações industriais as relações de interesse e poder, de conflito e cooperação, que coexistem nas relações de trabalho.

Entretanto, o autor propõe uma forma de utilização da teoria que o diferencia das demais vertentes por ele consideradas. Sugere articulá-la à teoria dos ciclos longos de Kondratieff ${ }^{17}$ a fim de situar a mudança nas relações capital X trabalho numa perspectiva histórica, oferecendo uma explicação tanto para o curto quanto para o longo prazo.

$\mathrm{O}$ recurso à teoria dos ciclos longos possibilita-lhe compreender as flutuações pelas quais passa o movimento dos trabalhadores como um processo normal e previsível, porque sincronizado ao ritmo da economia capitalista. Deste modo, os períodos de crescimento econômico são associados a uma curva de mobilização trabalhista ascendente, ao passo que uma fase de

${ }^{17}$ A maior parte dos trabalhos sobre relações industriais considera o papel do Estado enquanto legislador, empregador e definidor da política macroeconômica (ou como participante dos acordos tripartites, nos estudos sobre neocorporativismo), mas ignora sua relação com os interesses de classe e o processo de acumulação de capital (ou seja, passa longe da discussão sobre a natureza de classe do Estado, diferentemente de Hyman).

44 MARXISMO E RELAÇÕES DE TRABALHO 
crise econômica e ofensiva do capital corresponderia a uma curva de mobilização descendente, marcada pela redução do número de trabalhadores sindicalizados, diminuição da atividade grevista, mudanças nas formas de negociação coletiva, perda de legitimidade dos sindicatos e marginalização dos representantes sindicais, reafirmação das prerrogativas patronais, etc.

A idéia de ciclos que alternam mobilização e contra-mobilização sugere que a luta de classes é uma característica perene da sociedade capitalista. A fase de contra-mobilização, evidenciada pela redução dos conflitos de trabalho e pelo desenvolvimento de formas de cooperação entre trabalhadores e administração, longe de sinalizar o desaparecimento do antagonismo estrutural entre capital e trabalho, apenas demonstra que a ação coletiva tem uma lógica própria, é relativamente autônoma frente ao antagonismo estrutural que atravessa as relações de produção. Assim, o declínio de uma forma de ação coletiva - como o movimento operário clássico - não significa o fim da definição coletiva de interesses ou da própria organização sindical, mas somente indica que esta sofre transformações ligadas à introdução de novos padrões de relações industriais, contemplando a possibilidade da ação coletiva ressurgir sob formas diferentes. Nesse sentido, a ofensiva anti-sindical dos anos 70 e 80, não representa o fim dos sindicatos nem a supressão da ação coletiva: primeiro porque, embora o capital tenha buscado aumentar sua lucratividade e reafirmar a prerrogativa gerencial colocando-se contra a regulação conjunta com o sindicalismo, muitos empregadores continuam a reconhecer os sindicatos e a negociar com eles; segundo, porque o papel dos sindicatos não se restringe à negociação coletiva.

$* * * * * *$

Apesar da diversidade de posições dos autores marxistas aqui apresentados, seus trabalhos têm em comum o fato de atribuir um papel central aos conflitos de classe. Como vimos, conflitos podem ou não eclodir, mas as relações entre capital e trabalho apresentam certas regularidades que só podem ser entendidas a partir do conceito de classe e de dominação de classes.

A diferença de uma tradição marxista em relação às tradições não marxistas (para quem a ação coletiva é fruto do acaso, da somatória de von- 
tades/subjetividades individuais ou da existência de regras que definam as condições de sua manifestação) é que o marxismo considera que a ação coletiva é condicionada pela posição do indivíduo na estrutura social, ou seja, que "as funções estruturantes (econômica, política, jurídica, etc.) sobredeterminam uma divisão maior da sociedade em grandes 'atores' antagonistas: as classes sociais" ${ }^{\prime 18}$. No entanto, isso não quer dizer que o marxismo descarte a ação dos indivíduos: o materialismo de Marx é histórico e dialético; o movimento histórico é tecido a partir do entrecruzamento de elementos objetivos e subjetivos, sendo a classe em parte produto das atividades dos indivíduos e o resultado de suas lutas.

Finalmente, o estudo das relações sociais e políticas entre as classes deve levar em conta o processo de produção e de acumulação do capital, sem isolar a esfera das relações de trabalho do restante da sociedade. $\mathrm{O}$ conceito de relações sociais de produção inscreve as relações de trabalho numa relação política de dominação e numa relação econômica de exploração. Neste quadro, a divisão do trabalho, a organização do trabalho, as formas de negociação entre representantes de empregados e empregadores e os frutos dessa negociação não podem ser explicados por argumentos de ordem técnica, pois remetem às relações de poder na sociedade.

\footnotetext{
${ }^{18}$ Jacques Bidet, Jacques Texier, "Apresentation" [do dossiê consagrado à Sociologia da Ação]. Actuel Marx, n 13, 1993, p. 7.
}

46 MARXISMO E RELAÇÕES DE TRABALHO 